\title{
PSICOLOGÍA
}

\section{Resiliencia en familias de personas con Síndrome de Down en San Pedro del Paraná, Paraguay}

\author{
Liliana Ocampo', Fabiana Vargas Algarin¹
}

\begin{abstract}
Resumen
Introducción: En el ámbito de las enfermedades y discapacidades, la resiliencia familiar puede entenderse como proceso de adaptación y ajuste de la familia a las exigencias de la discapacidad. La resiliencia es un proceso dinámico, que tiene lugar a lo largo del tiempo y se sustenta en la interacción existente entre la persona y el entorno, entre la familia y el medio social. Es el resultado de un equilibrio entre factores de riesgo, factores protectores y personalidad de cada individuo, funcionalidad y estructura familiar. Una de las discapacidades intelectuales que actualmente presenta mayor sensibilización y visibilidad social es el síndrome de Down (SD). Se comprende que la presencia de esta discapacidad trae consigo situaciones a las familias quienes deben desarrollar las competencias necesarias para afrontar los problemas, la confianza, el apoyo mutuo y otros procesos claves para la resiliencia. Según los datos recogidos por Organización Mundial de la Salud (2014), en nuestro país existe una tasa importante de personas con SD. En el 2013 se han registrado 16.108 nacimientos de personas con este síndrome. La prevalencia de este trastorno es de 22,35 por cada 10.000 habitantes. En la ciudad de San Pedro del Paraná existe también una importante cantidad de personas con este síndrome; según el registro de la Asociación de Padres y Amigos de personas con Discapacidad (2014), asciende a 30 las personas. La relevancia de la presente investigación radica en la manera de cómo aborda la resiliencia desde una mirada familiar holística, cuyos componentes requieren estrategias múltiples altamente creativas para generar armonía en el seno familiar que incluye al hijo o hija con SD.
\end{abstract}

Objetivo: Describir los factores de resiliencia que presentan las familias de personas con síndrome de Down.

Material y Método: El estudio de caso comprendió 3 familias de la zona urbana de la ciudad de San Pedro del Paraná. Los instrumentos y técnicas de recolección de datos fueron: entrevista a profundidad grabadas aplicado a los padres de familias, la observación participante realizada en el momento de la entrevista y el Genograma Familiar que fue aplicado posteriormente. El

1. Facultad de Humanidades, Ciencias Sociales y Cultura Guaraní, Universidad Nacional de Itapúa, Paraguay.

E-mail: faby_93_var@hotmail.com

DOI: 10.26885/rcei.foro.2017.130 


\section{Resiliencia en familias de personas con Síndrome de Down. Ocampo y Vargas}

genograma es el diseño de un árbol ramificado que permite conocer en forma gráfica la constelación familiar multigeneracional.

Resultados: Las tres familias denotan factores protectores como sistemas de creencias compartidas que lo expresan en la fuerte fe en Dios, el cambio activo en los valores de vida, la perseverancia en hallar el bienestar psicosocial de sus hijos y la esperanza de afrontar situaciones adversas que se presentan. Dentro de los patrones organizacionales se denotaron interacciones placenteras dentro del núcleo familiar; humor, colaboración mutua entre los padres en la crianza de los hijos, la integración y aceptación de los demás hermanos hacia la persona con SD. En los procesos comunicativos una de las tres familias presenta antecedentes de relaciones conflictivas de pareja y comunicación distante entre los miembros que la conforma, las demás familias expresan sus emociones de manera clara, manteniendo una relación empática que contribuye a la cohesión familiar. Se identificaron factores de riesgos como poco ingreso económico en dos familias falta de participación en las redes sociales de apoyo y poco involucramiento de las figuras paternas.

Los temores de las familias les han hecho sentir vulnerables, por lo que han desarrollado las competencias necesarias para afrontarlas; el ajuste a las exigencias de la discapacidad es lo que hace resilientes a estas familias. Se ha generado respuestas familiares tales como: reconocer los problemas y limitaciones a los que se ven o vieron enfrentados principalmente en el contexto de carencias en torno a redes sociales de apoyo, instituciones médicas y de educación, hablando de manera clara respecto de las dificultades con que se encontraron y cómo organizaron estrategias distintas, evaluando sus logros y pérdidas, la capacidad que tienen las familias en ampliar las visiones a partir de los factores resilientes, frente a otras que han sido desechadas y comenzar un proceso de co-construcción junto a la familia, para darle un nuevo sentido a la idea de vida familiar.

Conclusiones: Al principio, en las familias, el impacto frente al diagnóstico de sus hijos generó mucha incertidumbre al aumentar las exigencias en el seno familiar. Se observó como el sentido de pertenencia familiar se refuerza y valida en actitudes de apoyo emocional mutuo y el funcionamiento del propio sistema en cuanto a sus roles, dinámica y pautas en general. Las madres son las que ejercen la jerarquía en la toma de decisiones y mayor comprensión empática generando un sostén de apoyo emocional. Los factores de riesgos aumentan la probabilidad de que las familias sean vulnerables ante ciertas situaciones estresantes. De las tres familias, dos exponen las carencias en cuanto a las muestras de afectos con las familias extensas y el poco ingreso económico para cubrir necesidades básicas. En cuanto a las relaciones emocionales evidenciadas en el genograma familiar, solo en una de las familias la relación es distante con algunos de sus miembros y con reglas rígidas dentro del sistema. Los casos de las familias estudiadas logran sobrellevar tanto el impacto del diagnóstico, la marginación, construyendo un relato a partir de este llamado proceso de afrontamiento. 
Palabras clave: resiliencia, familia, síndrome de Down, factores protectores, factores de riesgo.

\section{Referencias}

Barrios Cepeda, A. (2005). Autoconcepto y características familiares de niños resilientes con discapacidad el caso de una población del caribe colombiano. Investigación y Desarrollo, 13(1), 108-127. Recuperado de http://rcientificas.uninorte.edu.co/

Cunningham, C. C. (2000). Familias de niños con Sídrome de Down. En M. A. (Ed.), Familias y discapacidad intelectual. Madrid: FEAPS.

Down, E. (2012). Familias y Síndrome de Down. Recuperado de http://www. sindromedown.net/

Hodapp, R. (2008). Familas de las personas con Síndrome de Down. 25, 17-32.

Kleiman, A. (1989). Illness narratives: Suffering, healing and the human condition. En W. Froma (Ed.), Resiliencia Familiar. Estrategias para su fortalecimiento (p. 96). Buenos Aires: Amorrortu.

Walsh, F. (2004). Resiliencia familiar: estrategias para su fortalecimiento. Buenos Aires: Amorrortu. 